\title{
Gender Differences in Surgery for Work-Related Musculoskeletal Injury: A Population-Based Cohort Study
}

\section{Différences entre les sexes dans la chirurgie pour les blessures musculosquelettiques reliées au travail : une étude de cohortes axée sur la population}
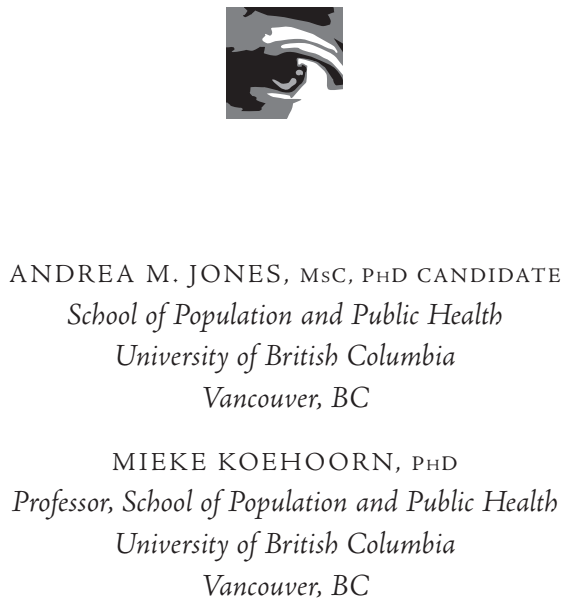


\begin{abstract}
Objective: The objective of this study is to examine if women are less likely than men to receive surgery following work-related musculoskeletal injury in the Canadian province of British Columbia.

Methods: The study included 2,403 workers with work-related knee meniscal tear, thoracic/ lumbar disc displacement or rotator cuff tear. Probability of surgery was compared by gender using Kaplan-Meier methods and Cox proportional hazards models.

Results: For each injury type, a smaller proportion of women received surgery compared to men (knee: $76 \%$ vs. $80 \%$; shoulder: $13 \%$ vs. $36 \%$; back: $13 \%$ vs. $19 \%$ ). In adjusted models, compared to men, women were 0.87 (95\% confidence interval [CI] [0.69, 1.09]), 0.35 (95\% CI $[0.25,0.48])$ and $0.54(95 \% \mathrm{CI}[0.31,0.95])$ times less likely to receive knee, shoulder or back surgery, respectively.

Conclusions: Probability of surgery following work-related musculoskeletal injury was lower for women than for men. Strategies to ensure gender equitable delivery of surgical services by workers' compensation systems may be warranted, although further research is necessary to investigate determinants of the gender difference and the impact of elective orthopaedic surgery on occupational outcomes.
\end{abstract}

\title{
Résumé
}

Objectif : Lobjectif de cette étude est de voir si les femmes sont moins susceptibles que les hommes de subir une chirurgie suite à une blessure musculosquelettique reliée au travail dans la province canadienne de la Colombie-Britannique.

Méthode : L'étude porte sur 2403 travailleurs qui ont eu des blessures au travail, soit une déchirure du ménisque du genou, un déplacement de disque dorsal/lombaire ou une rupture de la coiffe des rotateurs. La probabilité de subir une chirurgie a été comparée entre les sexes au moyen de la méthode de Kaplan-Meier et du modèle des hasards proportionnels de Cox. Résultats: Une plus petite proportion de femmes ont subi une chirurgie comparativement aux hommes, et ce, pour chaque type d'intervention (genou : $76 \%$ c. $80 \%$; épaule : $13 \%$ c. $36 \%$; dos : $13 \%$ c. $19 \%$ ). Selon les modèles ajustés, les femmes avaient, comparativement aux hommes, 0,87 (95\% intervalle de confiance [IC] [0,69-1,09]), 0,35 (95\% IC [0,23-0,48]) et $0,54$ (95\% IC $[0,31-0,95])$ moins de chance de subir une chirurgie pour le genou, l'épaule ou le dos, respectivement.

Conclusion: La probabilité de subir une chirurgie suite à une blessure musculosquelettique reliée au travail était moins élevée chez les femmes que chez les hommes. Des stratégies sont nécessaires pour assurer une prestation équitable des services chirurgicaux dans le cadre des régimes d'indemnisation des accidents du travail, mais il faut approfondir la recherche afin d'étudier les déterminants des différences entre les sexes ainsi que l'impact des chirurgies orthopédiques non urgentes sur les résultats professionnels. 


\section{Introduction}

"Identifying gender inequalities and addressing gender equity are ... central to good stewardship of health systems" (Payne 2009: Executive Summary). Gender differences in healthcare delivery have been documented for a number of conditions including congestive heart failure (Sheppard et al. 2005), colon cancer (Donovan and Syngal 1998), acute myocardial infarction (Arora et al. 2019; Jneid et al. 2008), critical illness (Fowler et al. 2007), renal disease (Bloembergen et al. 1997; Jindal et al. 2005) and hip and knee arthritis (Hawker et al. 2000; Travis et al. 2012). For each of these aforementioned findings, men were more likely to receive indicated health services than women. Although, such gender differences are not universal across conditions, populations or time because these are affected by culture, gender roles and other ecological factors.

Some of the strongest findings for gender differences in healthcare delivery have been for elective arthroplastic surgeries. Almost 20 years ago, an observational study (in 2000) found that in Canada, both men and women underused knee and hip arthroplasty, but the underuse was greater for women (Hawker et al. 2000). Interestingly, although women were as willing to undergo surgery as men, women were less likely to have discussed the possibility with a physician. Following this, a 2010 Canadian study used standardized patients to experimentally control for surgical indications and isolate the effects of patient gender on odds of recommendation for total knee arthroplasty. Results found that compared to women, men had twice the odds of recommendation from a family physician and 22 times the odds of recommendation from an orthopaedic surgeon (Borkhoff et al. 2008). Such findings are not limited to Canada. A 1996 American study found that men's odds of total hip arthroplasty were 1.26 times that of women's after controlling for confounders (Giacomini 1996). Likewise, an English study of gender differences in healthcare delivery leading up to total hip arthroplasty found that, after controlling for age, disease severity and willingness and fitness for surgery, women were less likely than men to consult their general practitioner, receive referral to specialist care, consult an orthopaedic surgeon and be on a surgical wait-list (Jüni et al. 2010). Differences in diagnostic indicators, care-seeking behaviours and willingness to undergo surgery have been unable to fully explain the differences in men's and women's use of arthroplastic surgery, and evidence indicates that physicians are more likely to recommend these surgeries to men than to women (Borkhoff et al. 2008, 2013; Hawker et al. 2000; Jüni et al. 2010). Susceptibility of physician's decision-making to subconscious gender-based stereotypes is a suggested explanation for this observed gender disparity in surgical decisionmaking (Borkhoff et al. 2008).

Little is known about gender differences in elective surgery for musculoskeletal conditions other than osteoarthritis. Surgical decision-making for other musculoskeletal conditions may also be susceptible to gender bias because of the elective nature of these surgeries and the cognitively complex process of interpreting multiple surgical indications and contraindications, some of which may intersect with stereotypical understandings of 
gender. Although gender differences in surgery for musculoskeletal conditions are of interest to health systems that serve general populations, these are also of special interest to health systems that serve working populations, such as workers' compensation systems where musculoskeletal conditions are a leading cause of disability and cost spending (Baldwin 2004; WorkSafeBC 2016).

In Canada, workers' compensation systems insure wage-loss benefits and health services for work-related injury and illness, whereas provincial public health systems insure physician and hospital services for non-work-related injury and illness. Policy and practice surrounding surgical healthcare delivery varies notably between these two parallel health systems (Hurley et al. 2008), warranting individual examination of both systems. For example, in the British Columbia workers' compensation system, case managers can opt to expedite orthopaedic surgery for injured workers by sending them to a private surgical facility (for an added cost), in lieu of a public facility where wait-lists are longer. Such practices may introduce additional mechanisms for gender bias not existent in provincial public health systems. Organizational mandates also vary between these two types of health system. Timely return to work is a more central focus for workers' compensation systems than for provincial public health systems. Return-to-work goals may have a greater influence on surgical decision-making when the condition is work-related and insured by workers' compensation, and this may affect men and women differently.

The objective of the current study was to examine gender differences in surgery among workers in British Columbia with accepted workers' compensation claims for musculoskeletal injury. The study focused on three common types of work-related musculoskeletal injury where surgery is a potential treatment option: knee meniscus tear, rotator cuff tear and thoracic/lumbar intervertebral disc displacement. To our knowledge, gender differences in surgery for these musculoskeletal conditions have not yet been examined in either general or working populations, and gender differences in healthcare delivery for work-related injury or illness have received relatively little attention in the occupational health literature. Based on findings from knee and hip osteoarthritis patients in the general population, we hypothesized that for each type of work-related musculoskeletal injury investigated, women would have lower probability of surgical treatment than men with the same injury, after adjusting for age, physical job demands and clinical characteristics.

\section{Methods}

This retrospective population-based cohort study was designed in accordance with The Strengthening the Reporting of Observational Studies in Epidemiology statement for reporting observational studies (von Elm et al. 2008).

\section{Data sources}

Individual-level, linked administrative data sets from WorkSafeBC (Workers' Compensation Board of British Columbia) and Ministry of Health were used (British Columbia Ministry 
of Health 2012a, b; WorkSafeBC 2012). During the study period, WorkSafeBC provided workers' compensation coverage for $94 \%$ of the provincial workforce (Association of Workers' Compensation Boards of Canada 2016), and all residents of British Columbia were required to be registered for public health insurance via the Ministry of Health.

\section{Study sample}

The study sample included workers with an accepted workers' compensation lost-time claim (at least one full day off work) for one of three common musculoskeletal injuries where surgical treatment could be a recommended treatment option: knee meniscus tear, rotator cuff tear and thoracic/lumbar intervertebral disc displacement with an injury date between May 1, 2009, and December 31, 2010. The study period was chosen based on the availability of the data. In the event that an individual had multiple claims meeting the eligibility criteria, only the first claim from the study period was retained for analysis.

Injury type was determined using four-digit International Classification of Diseases, Ninth Revision (ICD-9) codes recorded in the claims data set (836.2, 836.0 and 836.1 for knee meniscus tear; $840.4,840.5$ and 840.6 for rotator cuff tear; and 722.0 and 722.1 for thoracic/lumbar intervertebral disc displacement; Government of British Columbia 2017). The study sample was restricted to injured workers between the ages of 19 to 64 years who were registered for provincial healthcare during the year of injury, which was necessary to ensure 365 days of follow-up for surgical outcomes.

\section{Study variables}

Gender was the primary explanatory variable for all analyses and was ascertained from the self-reported "sex" field in the Ministry of Health data set. According to the Canadian Institutes of Health Research (2019), gender refers to socially constructed roles, behaviours, expressions and identities, whereas sex refers to biologically determined features including chromosomes, gene expression, hormone levels and function and reproductive/sexual anatomy. Because the "sex" field from the administrative data was self-reported, participants likely completed this field based on their gender identity (to the best of their ability with the options that were provided, i.e., male or female).

Although administrative records often lack measures of gender, disaggregation of the data based on sex can allow for analysis of gender issues (UNECE 2010), and this is the approach used here. Throughout this study, the term "gender" is used rather than "sex" because previous research indicates that differences in elective orthopaedic surgery between men and women are because of the effects of socially constructed gender roles on physician's surgical decision-making, rather than biological differences between men and women. Further, because sex is not a surgical indication for the conditions examined here, there is no reason to hypothesize that sex-based characteristics explain potential differences in the rates of surgery between men and women. 
Musculoskeletal surgery (yes/no and time to surgery in days) within 365 calendar days of the workers' compensation injury date was the primary outcome variable. Surgeries were identified using the Ministry of Health and workers' compensation data sets, and all major surgeries involving arthroscopic or arthrotomic access to the joint of interest were included. Surgical wait time was calculated as the number of calendar days from injury date to surgery date, censored at 365 days. A time frame of 365 calendar days was used to increase the probability that surgical outcomes were directly related to the injury from the included compensation claim. All holidays, weekends and business days were included in the calendar days measure. Individuals who received surgery on the same day as their injury were excluded from the study sample because such injuries represent probable traumatic injuries that require little discretionary decision-making about surgical treatment that might be influenced by gender.

Potential confounders included injury type (knee meniscus tear, rotator cuff tear or thoracic/lumbar intervertebral disc displacement), age at the time of injury, prior workers' compensation claim, occupational strength requirements and the primary body position associated with the occupation. For the knee meniscus injury sample, an additional variable for co-morbidity was included for knee ligament strain at the time of injury or in the 12 months following injury. This variable was defined as no knee strain diagnoses or one or more diagnoses from a non-musculoskeletal-related physician or one or more diagnoses from a musculoskeletal-related physician. Orthopaedic surgeons, physical medicine and rehabilitation physicians and radiologists were considered musculoskeletal-related physicians. Individuals with diagnoses for knee ligament strain from a non-musculoskeletal-related physician and from a musculoskeletal-related physician were categorized as having a diagnosis from the latter. Similar variables were not included for the rotator cuff and intervertebral disc injury samples because the incidence of co-morbid musculoskeletal diagnoses for these injuries was low.

For the prior workers' compensation claim variable, individuals were classified based on their history in the past five years: (1) no prior accepted workers' compensation claim, (2) one or more prior accepted workers' compensation claims with no direct pathophysiological relation to the injury of interest and (3) one or more prior workers' compensation claims with at least one of these claims having a direct pathophysiological relation to the injury of interest. Prior claims with diagnoses indicating internal injury to the same joint as the joint of interest were considered to have a direct pathophysiological relation, but by definition, each claim represents an independent injury or incident.

Occupational strength requirements were classified as limited (handling loads up to $5 \mathrm{~kg}$ ), light (handling loads of $5 \mathrm{~kg}$ but $<10 \mathrm{~kg}$ ), moderate (handling loads between $10 \mathrm{~kg}$ and $20 \mathrm{~kg}$ ) or heavy (handling loads of more than $20 \mathrm{~kg}$ ). The primary body position associated with the occupation was classified as sitting or other. Values for these two variables were obtained from the 2003 Career Handbook, published by Human Resources Development 
Canada (2003), which contains ratings for key occupational characteristics assigned by trained occupational analysts using a Delphi procedure. For the current study, ratings from the Handbook were assigned to workers based on the occupation code associated with the claim.

\section{Analysis}

All analyses were conducted using SAS 9.4 (SAS 2017). Ethical approval for the research project was obtained from the Behavioural Research Ethics Board at the University of British Columbia (H12-02239). All analyses were stratified by injury type.

The cumulative probability of surgery by wait time was compared for men and women using Kaplan-Meier methods and the log-rank test. The probability of women undergoing surgery relative to men on any day following injury was estimated using unadjusted and adjusted Cox regression models (Cox 1972). In addition to gender, adjusted models included the potential confounders of age, prior claim, occupational strength demands, primary body position associated with the occupation and, in the case of the knee sample, co-morbid diagnosis of knee ligament strain. The proportional hazards assumption was assessed graphically (Kaplan-Meier and log-minus-log plots) and by examining interactions with the log of the wait time variable. Only interaction terms for time-varying variables, significant at a $95 \%$ level of confidence, were retained in the final adjusted models.

Finally, sensitivity analysis was conducted to examine the proportion of surgeries in the study sample covered by workers' compensation insurance as well as the effects of restricting the outcome to only surgeries covered by workers' compensation insurance. For the latter, follow-up time was censored on the day of the first surgery if the surgery was covered by the public health system rather than workers' compensation insurance.

\section{Results}

\section{Study sample}

A total of 2,545 unique accepted lost-time claims for knee meniscal tears $(n=687)$, rotator cuff tears $(n=1,105)$ and thoracic/lumbar intervertebral disc displacements $(n=753)$ were identified in the workers' compensation data set, with injury dates occurring between May 1 , 2009, and December 31, 2010. Of the 2,545 claims, 142 (5.6\%) were removed because of one or more of the following: age of $<19$ or $>64$ years, not registered for provincial healthcare, missing data for gender or age, receipt of surgical treatment on the same day as the injury or the claim was not the first musculoskeletal injury for a worker during the follow-up period. The final study sample consisted of 2,403 included claims (knee meniscal tear $=640$; rotator cuff tear $=1,042$; intervertebral disc displacement $=721$ ). 


\section{Knee meniscus injury sample}

The meniscus injury sample was approximately one fifth of women (20.9\%), with a similar mean age for women (47 years) and men ( 45 years). Approximately $13 \%$ of both women and men had a related prior claim, although men were more likely than women to have had an unrelated prior claim (49.4\% vs. 39.6\%). Men and women had different occupational strength demands (Table 1, available online at longwoods.com/content/26131). In particular, compared with women (10.5\%), men were more likely to work in occupations with heavy strength demands (27.2\%). Approximately $70 \%$ of both men and women had received a diagnosis of co-morbid knee ligament strain from either a non-surgical or a surgical specialist.

\section{Rotator cuff injury sample}

The rotator cuff injury sample consisted of approximately one third of women (34.4\%), and the mean age was the same for women and men (46 years; Table 1 ). Women were more likely than men to have no prior claim (40.5\% vs. $34.9 \%)$, whereas men were more likely than women to have an unrelated prior claim (55.3\% vs. $46.9 \%)$. Men and women had different strength demands associated with their occupation at the time of injury, with a higher proportion of men having heavy occupational strength demands $(25.6 \%)$ compared to women (5.3\%).

\section{Intervertebral disc displacement injury sample}

The intervertebral disc displacement injury sample was just over one-quarter women (27.0\%), with a similar mean age for women (43 years) and men (41 years; Table 1 ). Women were more likely than men to have no prior claim (49.7\% vs. $35.4 \%)$, whereas men were more likely than women to have an unrelated prior claim (41.6\% vs. $31.3 \%)$. Again, compared to women (7.6\%), men were more likely to work in an occupation with heavy occupational strength demands (25.5\%).

Overall, across the three injury samples, the distributions of the injured workers' age, prior claim status, occupational strength demands and occupational body position by gender were very similar.

\section{Gender and surgery}

Musculoskeletal surgery was most common in the meniscus sample with 509 workers (79.1\%) with this injury receiving surgery within 12 months. A smaller proportion of workers from the rotator cuff $(n=294,28.2 \%)$ and intervertebral disc $(n=125,17.3 \%)$ samples went on to undergo surgery. Descriptively, by 365 days, the cumulative probability of surgery was higher for men than for women for all samples (Figure 1). Gender showed evidence of nonproportionality for the intervertebral disc sample. For this sample, gender had no effect on the probability of surgery within the first 90 days following injury $\left(\chi^{2}=0.00, p=0.9697\right)$, 
after which men were more likely to receive surgery than women. Relatively few surgeries were observed in the intervertebral disc sample prior to 91 days $(4.6 \%$ of women $[n=9]$ and $4.6 \%$ of men $[n=24])$. To account for this in the current study, analyses for the intervertebral disc sample were stratified by time and only results from the 91-to-365-day strata are reported for the Kaplan-Meier and Cox regression analyses. In the Kaplan-Meier analyses, the unadjusted effect of gender on wait time was significant for the rotator cuff $\left(\chi^{2}=57.05\right.$, $p<0.0001)$ and intervertebral disc (91 to 365 days; $\chi^{2}=5.02, p=0.0250$ ) samples but not the meniscus sample $\left(\chi^{2}=1.86, p=0.1729\right)$.

FIGURE 1. Cumulative probability of surgery by wait time and injury type for women and men with accepted workers' compensation claims
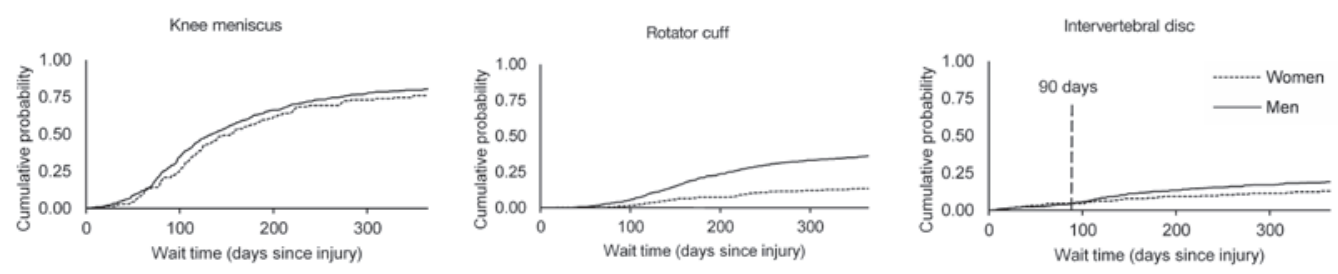

For the study confounders in unadjusted Cox regression models, age showed evidence of non-proportionality with surgery in the meniscus sample but not the intervertebral disc and rotator cuff samples. To account for this, an interaction term between age and the log of the wait time variable was included in the adjusted Cox regression model for the meniscus sample. Using men as the reference group, the unadjusted effect of gender in the Cox regression models was significant for the intervertebral disc (hazard ratio $[\mathrm{HR}]=0.55,95 \%$ confidence interval $[\mathrm{CI}][0.32,0.93])$ and rotator cuff $(\mathrm{HR}=0.32,95 \% \mathrm{CI}[0.24,0.44])$ samples but not the meniscus sample (HR $=0.86,95 \%$ CI $[0.69,1.07])$. Similar results were found for the full models adjusted for age, prior claim, strength demands, body position and knee ligament strain (knee sample only). The HRs for gender in the adjusted models for the intervertebral disc, rotator cuff and meniscus samples were 0.54 (95\% CI [0.31, 0.95]), 0.35 (95\% CI [0.25, $0.48]$ ) and 0.87 (95\% CI $[0.69,1.09])$, respectively (Table 2).

In the sensitivity analysis, $95.3 \%$ of knee (485 of 509), 94.2\% of shoulder (277 of 294) and $79.2 \%$ of back (99 of 125) surgeries were covered by workers' compensation insurance. When the surgical outcome was restricted to surgeries covered by workers' compensation insurance, the HRs and 95\% CIs for the gender variable in the adjusted Cox regression models were similar to those found in the primary analysis (intervertebral disc - HR $=0.53,95 \%$ $\mathrm{CI}=[0.28,0.99]$; rotator cuff $-\mathrm{HR}=0.34,95 \% \mathrm{CI}[0.24,0.47]$; knee meniscus $-\mathrm{HR}=$ $0.83,95 \%$ CI $[0.66,1.04])$. 
TABLE 2. Adjusted hazard ratios with 95\% confidence intervals for surgery for workers with accepted workers' compensation claims stratified by injury type.

\begin{tabular}{|c|c|c|c|}
\hline & \multicolumn{3}{|c|}{ Adjusted hazard ratio ( $95 \%$ confidence interval) } \\
\hline & Knee meniscus tear & Rotator cuff tear & Intervertebral disc ${ }^{\mathrm{a}}$ \\
\hline $\begin{array}{l}\text { Gender } \\
\text { Men } \\
\text { Women }\end{array}$ & । $0.87[0.69,1.09]$ & $0.35[0.25,0.48]$ & $0.54[0.31,0.95]$ \\
\hline $\begin{array}{l}\text { Age } \\
\qquad \text { Age } \times \log (\text { wait time })\end{array}$ & $\begin{array}{l}0.85[0.81,0.91] \\
1.04[1.02,1.05]\end{array}$ & $\begin{array}{l}\text { I.04 }[1.03,1.06] \\
\text { Not significant }\end{array}$ & $\begin{array}{l}0.98[0.96,1.00] \\
\text { Not significant }{ }^{b}\end{array}$ \\
\hline $\begin{array}{l}\text { Prior claim } \\
\text { None } \\
\text { Other body part } \\
\text { Same body part }\end{array}$ & $\begin{array}{l}\text { I } \\
0.91[0.76,1.09] \\
1.46[1.13,1.89]\end{array}$ & $\begin{array}{l}\text { I } \\
0.98[0.78,1.25] \\
0.95[0.64,1.40]\end{array}$ & $\begin{array}{l}\text { । } \\
0.85[0.56,1.29] \\
0.86[0.52,1.43]\end{array}$ \\
\hline $\begin{array}{l}\text { Strength demands } \\
\text { Limited } \\
\text { Light } \\
\text { Medium } \\
\text { Heavy }\end{array}$ & $\begin{array}{l}\text { I } \\
\text { I. } 16[0.85,1.58] \\
1.09[0.85,1.40] \\
1.13[0.84,1.51]\end{array}$ & $\begin{array}{l}\text { I } \\
0.83[0.53,1.27] \\
0.77[0.55,1.09] \\
1.33[0.89,1.99]\end{array}$ & $\begin{array}{l}\text { I } \\
0.75[0.36,1.57] \\
0.92[0.51,1.66] \\
0.82[0.40,1.68]\end{array}$ \\
\hline $\begin{array}{l}\text { Body position } \\
\text { Sitting } \\
\text { Other }\end{array}$ & $\begin{array}{l}\text { I } \\
0.77[0.60,0.99]\end{array}$ & $0.89[0.65,1.22]$ & ।.0। $[0.56,1.84]$ \\
\hline $\begin{array}{l}\text { Knee strain } \\
\text { None } \\
\text { Diag phys } \\
\text { Diag msk phys }\end{array}$ & $\begin{array}{l}\text { । } \\
1.20[0.96,1.49] \\
1.33[1.08,1.64]\end{array}$ & Not applicable & Not applicable \\
\hline
\end{tabular}

a Time stratified analysis with only the 91 -to-365-day strata reported here

b Interaction with the log of the wait time variable was examined for all study covariates. Only interaction terms significant at a $95 \%$ level of confidence were included in the adjusted analyses.

c Diagnosis for co-morbid knee ligament strain from a physician

d Diagnosis for co-morbid knee ligament strain from a musculoskeletal-related physician

\section{Discussion}

This study examined the relationship between gender and surgery among workers with accepted lost-time claims for musculoskeletal injury in the Canadian province of British Columbia. We found that after adjustment for confounders, women's probability of surgery for work-related knee meniscus tears, rotator cuff tears and intervertebral disc displacements was lower (0.87, 0.35 and 0.54 times, respectively) than men's. The findings are in agreement with those reported in literature from general populations, that is, women are less likely than men to receive hip or knee replacement surgery (Borkhoff et al. 2008; Giacomini 1996; Hawker et al. 2000; Jüni et al. 2010). The current study expands the knowledge base on gender differences in elective orthopaedic surgery to a workers' compensation population and to three types of common work-related musculoskeletal injury not previously reported on. Furthermore, after restricting the outcome to surgeries paid for by the workers' compensation system, women's probability of surgery was lower than men's probability. This demonstrates that the gender bias found in this study is not because of surgeries paid for solely by the public health system.

In our study, gender differences in surgery were more pronounced when surgery was not 
the standard course of treatment, as was the case with work-related thoracic/lumbar disc displacements and rotator cuff tears. Respectively, less than $20 \%$ and $30 \%$ of workers with these injuries went on to undergo surgery. Conversely, nearly $80 \%$ of workers with knee meniscal tears went on to undergo surgery as a standard course of treatment. Women with knee meniscal tears were still less likely to undergo surgery than men, although the effect size was smaller and not statistically significant. Evidence shows that stereotypes have a larger impact on healthcare providers' clinical decision-making when there is an element of uncertainty or when the care provider experiences a high cognitive load (Burgess et al. 2004; Burgess 2010; Chinburapa et al. 1993; Hall 2002). Given this, we hypothesize that when surgery is a standard course of treatment, as was the case for knee meniscal tears in the study sample, there is less perceived uncertainty regarding indication for surgery, and clinical decision-making is less susceptible to bias by patient or worker gender.

The evidence base regarding the efficacy of the surgeries examined here is evolving. Recent systematic reviews have concluded unclear or no long-term benefits for arthroscopic knee meniscectomy and/or debridement, lumbar disc discectomy and open or arthroscopic subacromial decompression compared with non-surgical treatments (Coghlan et al. 2008; Gibson and Waddell 2007; Khan et al. 2014; Thorlund et al. 2015). As these findings are taken up into practice, surgeries that are currently the standard course of treatment, such as knee meniscectomy, may become less common. Should this be the case, physicians' tendency to refer men for surgery more often than women, especially in uncertain situations that involve higher degrees of discretionary decision-making, must be considered. A more conservative rate of elective surgery for musculoskeletal injury, as is currently the case for women compared to men, may be a preferred outcome.

Non-proportionality of the gender variable was observed in the intervertebral disc injury sample. No effect of gender was observed in the first 90 days following injury; however, from 91 to 365 days, men were more likely to receive surgery than women. Use of surgery during the first 90 days following intervertebral disc injury was low, and this likely reflects conservative use of surgery for this injury during this acute phase of injury when the prospect of return to work without surgical intervention is high (Frank et al. 1998). This finding is in line with clinical guidelines that recommend surgical discectomy only when pain is persistent and does not resolve with less invasive treatment (Chou et al. 2007).

Perception that return to work is of greater importance to men may lead physicians to refer men with work-related injury for surgery more often than women or to prioritize men's position on the wait-list. In Western cultures, men's status on the masculine hierarchy is strongly determined by their ability to produce income and/or the physicality of their work (Evans et al. 2011; Lee and Owens 2002). Inability to work due to health reasons, or inability to engage in physical labour, has a significant impact on masculine identities, more so than feminine ones (Evans et al. 2011; Lee and Owens 2002; Ostrander 2008). Further, based on recent Canadian estimates, men are over twice as likely as women to be the higher income recipient in an adult couple (Statistics Canada 2017). This may also contribute to the 
perception that return to work is of greater importance for men, as in married or co-habiting heterosexual couples, as the household may be more reliant on men's income. For these reasons, physicians may be more likely to discuss surgery with men than with women or to refer men for surgery more often than women, because of disability-masculinity role conflict in the context of work disability and return-to-work outcomes and men's role as the higher income recipient within a household. These hypotheses are supported by the finding that in the general Canadian population, men have been shown to be more likely than women to have discussed the possibility of joint replacement surgery with a physician (Hawker et al. 2000). Such gendered perceptions could also affect decision-making in the workers' compensation system related to wait time for surgery where additional decisions are made about expediting surgery to improve return to work (Hurley et al. 2008). In the current study, men with musculoskeletal injuries were more likely to be in occupations with heavy physical demands than women. The perception that surgery is needed to be able to return to work more quickly for these types of occupations, particularly for men, may have added to the gender differences reported here.

There are some limitations to the current study. First, to control for injury severity, inclusion was limited to a small set of International Classification of Diseases, Ninth Revision diagnoses. Furthermore, the study sample was limited to lost-time claims, ensuring that all injuries were severe enough to warrant time off work, and injuries severe enough to result in same-day surgery were excluded. Despite this, the possibility of some remaining heterogeneity of injury severity cannot be entirely dismissed. This could cause differential bias if injury severity were associated with gender. However, there is little evidence to support such an association. In the meniscus injury sample, a measure of co-morbid knee ligament strain was developed to control for injury severity in the form of damage to multiple structures of the knee. This variable was related to surgery but not gender, demonstrating that in this instance, injury severity did not confound the relationship between gender and surgery. In addition to this, the models were adjusted for occupational strength demands to account for the possibility that workers with heavy occupational strength demands might have sustained more serious injuries, and the models were also adjusted for prior claims to control for potential differences in pathophysiological history of the injury as well as potential co-morbidities. Second, although the potential confounders of occupational strength demands (classified as limited, light, moderate or heavy based on the strength involved in the handling of objects) and the primary body position associated with the job (sitting vs. other) were included in the adjusted models, there was no available measure to capture the frequency of motion. Third, we were not able to control for workers' willingness to undergo surgery, and this may have contributed to the findings. However, a study on men's and women's use of elective hip or knee arthroplasty in the general Canadian population found that despite women's lower use of surgery, men and women were equally willing to undergo surgery (Hawker et al. 2000). 
The authors concluded that women's lower rate of surgery was most likely due to the barriers that exist at the level of the doctor-patient interaction. Based on this, we hypothesize that a similar phenomenon is occurring here in that the results are not predominantly driven by a difference in men's and women's willingness to undergo surgery but rather a gender difference in the number and type of barriers encountered in the pathway of care. Fourth, the data did not allow us to examine surgery for non-work-related injuries, and thus, we are not able to isolate if the observed gender differences are unique to work-related injuries in a workers' compensation population or if these are a reflection of gender differences present in the general population. Finally, our findings may not be generalizable to worker populations where the policy and practice surrounding treatment of work-related musculoskeletal injury diverges from that used in British Columbia.

In conclusion, this study demonstrated a higher probability of surgery for men with work-related musculoskeletal injury compared to similar women with the same injury. Additional studies are needed to better understand if the results presented here represent a gender inequity in terms of underuse of surgery and/or extended surgical wait times for women versus overuse and/or expedited wait times for men, as well as the underlying mechanisms. As mentioned earlier, physicians' tendency to under-refer women for surgery may be an unintended beneficial outcome for women, especially in the context of newly emerging evidence to suggest non-efficacy. Further research is also needed to better understand how surgery following work-related musculoskeletal injury affects disability and occupational outcomes for men and women. With a better understanding of these issues, interventions to ensure gender-equitable treatment of work-related musculoskeletal injury can be developed. Potential interventions to address gender differences in surgery for work-related musculoskeletal injury that occur due to biased decision-making include training and awareness programs as well as the implementation and enforcement of standardized guidelines and protocols. Although we are not aware of existing interventions specific to gender differences in surgery for work-related musculoskeletal injury, or musculoskeletal injury in general, similar interventions have reduced disparities, improved patient outcomes and decreased physicians' likelihood of making a biased decision in other areas of healthcare delivery (Hannah and Carpenter-Song 2013; Herbert et al. 2010; Mosca et al. 2011; Stone and Moskowitz 2011; Teal et al. 2012; Wang et al. 2011). Ultimately, research of this kind will help workers' compensation systems determine the best use of surgical services to manage work-related musculoskeletal injury in a gender-equitable manner and reduce disability and improve return to work for men and women.

\section{Disclaimer}

All inferences, opinions and conclusions drawn in this article are those of the authors, and do not reflect the opinions or policies of the data stewards. 


\section{Conflict of interest}

The authors have no conflict of interest to disclose.

\section{Acknowledgements and funding}

This study and Koehoorn were supported in part by a Canadian Institutes of Health Research Chair in Gender, Work and Health. McLeod was supported in part by a Michael Smith Health Research Foundation Scholar Award and a Canadian Institutes of Health Research New Investigator Award. Jones was supported in part by the CIHR Bridge Strategic Training Program and by research training awards from WorkSafeBC and the Centre for Research on Work Disability Policy. Jones, Koehoorn and McLeod were supported in part through the Partnership for Work, Health and Safety, a research partnership between WorkSafeBC (provincial workers' compensation system) and the University of British Columbia.

Correspondence may be directed to: Andrea M. Jones. Her e-mail address is andrea.jones@alumni. ubc.ca.

\section{References}

Arora, S., G.A. Stouffer, A.M. Kucharska-Newton, A. Qamar, M. Vaduganathan, A. Pandey et al. 2019. Twenty Year Trends and Sex Differences in Young Adults Hospitalized with Acute Myocardial Infarction: The ARIC Community Surveillance Study. Circulation 139(8): 1047-56. doi:10.1161/ CIRCULATIONAHA.118.037137.

Association of Workers' Compensation Boards of Canada (AWCBC). 2016. Detailed Key Statistical Measures Report. Retrieved November 5, 2017. <http://awcbc.org/?page_id=9759>.

Baldwin, M.L. 2004. Reducing the Costs of Work-Related Musculoskeletal Disorders: Targeting Strategies to Chronic Disability Cases. Journal Electromyography and Kinesiology 14(1): 33-41. doi:10.1016/j. jelekin.2003.09.013.

Bloembergen, W.E., E.A. Mauger, R.A. Wolfe and F.K. Port. 1997. Association of Gender and Access to Cadaveric Renal Transplantation. American Journal of Kidney Diseases 30(6): 733-38. doi:10.1016/ S0272-6386(97)90076-7.

Borkhoff, C.M., G.A. Hawker, H.J. Kreder, R.H. Glazier, N.N. Mahomed and J.G. Wright. 2008. The Effect of Patients' Sex on Physicians' Recommendations for Total Knee Arthroplasty. CMAJ 178(6): 681-87. doi:10.1503/cmaj.071168.

Borkhoff, C.M., G.A. Hawker, H.J. Kreder, R.H. Glazier, N.N. Mahomed and J.G. Wright. 2013. Influence of Patients' Gender on Informed Decision Making Regarding Total Knee Arthroplasty. Arthritis Care and Research 65(8): 1281-90. doi:10.1002/acr.21970.

British Columbia Ministry of Health. 2012a. Medical Services Plan (MSP) Payment Information File. Vancouver, BC: Population Data BC.

British Columbia Ministry of Health. 2012b. Consolidation File (MSP Registration E Premium Billing. Vancouver, BC: Population Data BC.

Burgess, D.J., S.S. Fu and M. van Ryn. 2004. Why Do Providers Contribute to Disparities and What Can Be Done About It? Journal of General Internal Medicine 19(11): 1154-59. doi:10.1111/j.1525-1497.2004.30227.x.

Burgess, D.J. 2010. Are Providers More Likely to Contribute to Healthcare Disparities Under High Levels of Cognitive Load? How Features of the Healthcare Setting May Lead to Biases in Medical Decision Making. Medical Decision Making 30(2): 246-57. doi:10.1177/0272989X09341751. 
Canadian Institutes of Health Research (CIHR). 2019. How to Integrate Sex and Gender into Research. Retrieved April 29, 2019. <http://www.cihr-irsc.gc.ca/e/50836.html>.

Chinburapa, V., L.N. Larson, M. Brucks, M. Draugalis, J.L. Bootman and C.P. Puto. 1993. Physician Prescribing Decisions: The Effects of Situational Involvement and Task Complexity on Information Acquisition and Decision Making. Social Science and Medicine 36(11): 1473-82. doi:10.1016/0277-9536(93)90389-L.

Chou, R., A. Qaseem, V. Snow, D. Casey, J.T. Cross, P. Shekelle et al. 2007. Clinical Guidelines Diagnosis and Treatment of Low Back Pain: A Joint Clinical Practice Guideline from the American College of Physicians and the American Pain Society. Annals of Internal Medicine 147(7): 478-91. doi:10.7326/0003-4819-147-7-200710020-00006.

Coghlan, J.A., R. Buchbinder, S. Green, R.V. Johnston and S.N. Bell. 2008. Surgery for Rotator Cuff Disease. Cochrane Database Systematic Review (1): CDOO5619. doi:10.1002/14651858.CD005619.pub2.

Cox, D.R. 1972. Regression Models and Life-Tables. Journal of the Royal Statistical Society Series B (Methodological) 34(2): 187-220. Retrieved February 4, 2020.

Donovan, J.M. and S. Syngal. 1998. Colorectal Cancer in Women: An Underappreciated but Preventable Risk. Journal of Women's Health 7(1): 45-48. doi:10.1089/jwh.1998.7.45.

Evans, J., B. Frank, J.L. Oliffe and D. Gregory. 2011. Health, Illness, Men and Masculinities (HIMM): A Theoretical Framework for Understanding Men and Their Health. Journal of Men's Health 8(1): 7-15. doi:10.1016/j.jomh.2010.09.227.

Fowler, R.A., N. Sabur, P. Li, D.N. Juurlink, R. Pinto, M.A. Hladunewich et al. 2007. Sex- and Age-Based Differences in the Delivery and Outcomes of Critical Care. CMAJ 177(12): 1513-19. doi:10.1503/cmaj.071112.

Frank, J., S. Sinclair, S. Hogg-Johnson, H. Shannon, C. Bombardier, D. Beaton et al. 1998. Preventing Disability from Work-Related Low-Back Pain. New Evidence Gives New Hope - If We Can Just Get All the Players Onside. CMAJ 158(12): 1625-31.

Giacomini, M.K. 1996. Gender and Ethnic Differences in Hospital-Based Procedure Utilization in California. Archives of Internal Medicine 156(11): 1217-24. doi:10.1001/archinte.1996.00440100115013.

Gibson, J.N. and G. Waddell. 2007. Surgical Interventions for Lumbar Disc Prolapse: Updated Cochrane Review. Spine 32(16): 1735-47. doi:10.1097/BRS.0b013e3180bc2431.

Government of British Columbia. 2017. Diagnostic Code Descriptions (ICD-9). Retrieved November 5 , 2017. <http://www2.gov.bc.ca/gov/content/health/practitioner-professional-resources/msp/physicians/ diagnostic-code-descriptions-icd-9>.

Hall, K.H. 2002. Reviewing Intuitive Decision-Making and Uncertainty: The Implications for Medical Education. Medical Education 36(3): 216-24. doi:10.1046/j.1365-2923.2002.01140.x.

Hannah, S.D. and E. Carpenter-Song. 2013. Patrolling Your Blind Spots: Introspection and Public Catharsis in a Medical School Faculty Development Course to Reduce Unconscious Bias in Medicine. Culture, Medicine, and Psychiatry 37(2): 314-39. doi:10.1007/s11013-013-9320-4.

Hawker, G.A., J.G. Wright, P.C. Coyte, I. Williams, B. Harvey, R. Glazier et al. 2000. Differences between Men and Women in the Rate of Use of Hip and Knee Arthroplasty. New England Journal of Medicine 342(14): 1016-22. doi:10.1056/NEJM200004063421405.

Herbert, K.H., B. Lopez, R. Horswell, L. Tamariz, A. Palacio, H. Li et al. 2010. The Impact of a Standardized Disease Management Program on Race/Ethnicity and Gender Disparities in Care and Mortality. Journal of Health Care for the Poor and Underserved 21(1): 264-76. doi:10.1353/hpu.0.0243.

Human Resources Development Canada. 2003. Career Handbook (Revised) (2nd edn). Ottawa, ON: Government of Canada.

Hurley, J., D. Pasic, J.N. Lavis, A.J. Culyer, C. Mustard and W. Gnam. 2008. Parallel Payers and Preferred Access: How Canada's Workers' Compensation Boards Expedite Care for Injured and Ill Workers. Healthcare Papers 8(3): 6-14. doi:10.12927/hcpap.2008.19792.

Jindal, R.M., J.J. Ryan, I. Sajjad and M.H. Murthy. 2005. Kidney Transplantation and Gender Disparity. American Journal of Nephrology 25(5): 474-83. doi:10.1159/000087920. 
Andrea M. Jones et al.

Jneid, H., G.C. Fonarow, C.P. Cannon, A.F. Hernandez, I.F. Palacios, A.O. Maree et al. 2008. Sex Differences in Medical Care and Early Death after Acute Myocardial Infarction. Circulation 118: 2803-10. doi:10.1161/ CIRCULATIONAHA.108.789800.

Jüni, P., N. Low, S. Reichenbach, P.M. Villiger, S. Williams and P.A. Dieppe. 2010. Gender Inequity in the Provision of Care for Hip Disease: Population-Based Cross-Sectional Study. Osteoarthritis and Cartilage 18(5): 640-45. doi:10.1016/j.joca.2009.12.010.

Khan, M., N. Evaniew, A. Bedi, O.R. Ayeni and M. Bhandari. 2014. Arthroscopic Surgery for Degenerative Tears of the Meniscus: A Systematic Review and Meta-Analysis. CMAJ 186(14): 1057-64. doi:10.1503/ cmaj.140433.

Lee, C. and R.G. Owens. 2002. Issues for a Psychology of Men's Health. Journal of Health Psychology 7(3): 209-17. doi:10.1177/1359105302007003215.

Mosca, L., E.J. Benjamin, K. Berra, J.L. Bezanson, R.J. Dolor, D.M. Lloyd-Jones et al. 2011. EffectivenessBased Guidelines for the Prevention of Cardiovascular Disease in Women-2011 Update: A Guideline from the American Heart Association. Circulation 123(11): 1243-62. doi:10.1161/CIR.0b013e31820faaf8.

Ostrander, R.N. 2008. When Identities Collide: Masculinity, Disability and Race. Disability and Society 23(6): 585-97. doi:10.1080/09687590802328451.

Payne, S. 2009. Policy Brief 12. How Can Gender Equity be Addressed through Health Systems? Copenhagen, Denmark: World Health Organization Regional Office for Europe. Retrieved February 4, 2020. <http://www. euro.who.int/__data/assets/pdf_file/0006/64941/E92846.pdf>.

SAS. 2017. Version 9.4. Cary, NC: SAS Institute.

Sheppard, R., H. Behlouli, H. Richard and L. Pilote. 2005. Effect of Gender on Treatment, Resource

Utilization, and Outcomes in Congestive Heart Failure in Quebec, Canada. The American Journal of Cardiology 95(8): 955-59. doi:10.1016/j.amjcard.2004.12.033.

Statistics Canada. 2017. Household Income in Canada: Key Results from the 2016 Census. Retrieved May 6, 2019. <https://www150.statcan.gc.ca/n1/daily-quotidien/170913/dq170913a-eng.htm>.

Stone, J. and G.B. Moskowitz. 2011. Non-Conscious Bias in Medical Decision Making: What Can be Done to Reduce It? Medical Education 45(8): 768-76. doi:10.1111/j.1365-2923.2011.04026.x.

Teal, C.R., A.C. Gill, A.R. Green and S. Crandall. 2012. Helping Medical Learners Recognize and Manage Unconscious Bias toward Certain Patient Groups. Medical Education 46(1): 80-88. doi:10.1111/j.1365-2923.2011.04101.x.

Thorlund, J.B., C.B. Juhl, E.M. Roos and L.S. Lohmander. 2015. Arthroscopic Surgery for Degenerative Knee: Systematic Review and Meta-Analysis of Benefits and Harms. BMJ 350: h2747: 1-9. doi:10.1136/bmj.h2747.

Travis, C.B., D.M. Howerton and D.M. Szymanski. 2012. Risk, Uncertainty, and Gender Stereotypes in Healthcare Decisions. Women and Therapy 35(3-4): 207-20. doi:10.1080/02703149.2012.684589.

United Nations Economic Commission for Europe (UNECE). 2010. Developing Gender Statistics: A Practical Tool: Reference Manual Prepared by the UNECE Task Force on Gender Statistics Training for Statisticians with Contributions from Various Experts. Geneva, Switzerland: United Nations. Retrieved March 9, 2019. <http:// www.unece.org/fileadmin/DAM/stats/publications/Developing_Gender_Statistics.pdf>.

von Elm E., D.G. Altman, M. Egger, S.J. Pocock, P.C. Gøtzsche, J.P. Vandenbroucke et al. 2008. The Strengthening the Reporting of Observational Studies in Epidemiology (STROBE) Statement: Guidelines for Reporting Observational Studies. Journal of Clinical Epidemiology 61(4): 344-49. doi:10.1016/j.

jclinepi.2007.11.008.

Wang, T.Y., D. Dai, A.F. Hernandex, D.L. Bhatt, P.A. Heidenreich, G.C. Fonarow et al. 2011. The Importance of Consistent, High Quality Acute Myocardial Infarction and Heart Failure Care: Results from the American Heart Association's Get with The Guidelines Program. Journal of the American College of Cardiology 58(6): 637-44. doi:10.1016/j.jacc.2011.05.012.

WorkSafeBC. 2012. Claims and Firm Level Files. Vancouver, BC: Population Data BC.

WorkSafeBC. 2016. 2015 Statistics. Retrieved February 5, 2017. <https://www.worksafebc.com/en/resources/ about-us/annual-report-statistics/2015-stats?lang=en $>$. 